\title{
A minimally invasive surgical treatment for inappropriate sinus tachycardia
}

\author{
Daniel Kreisel, MD, ${ }^{a}$ Marci Bailey, MD, ${ }^{a}$ Bruce D. Lindsay, MD, ${ }^{\mathrm{b}}$ and Ralph J. Damiano, Jr, MD, ${ }^{\text {a }}$ St Louis, Mo
}

I nappropriate sinus tachycardia (IST) is a rare disorder characterized by an abnormally elevated heart rate at rest and an exaggerated rate response to physical activity. In most patients the condition is refractory to dietary modification and medical management. Despite reports of successful catheter ablation of the sinoatrial node, patients do fail to respond to this therapy. ${ }^{1,2}$ This report describes a case of IST, refractory to medical therapy and catheter ablation, that was successfully treated surgically with a novel minimally invasive off-pump approach.

\section{Clinical Summary}

A 34-year-old woman was referred for surgical treatment of IST. She had initially presented at the age of 28 years with reports of palpitations associated with chest pain and shortness of breath. An echocardiogram and a cardiac catheterization showed unremarkable results. Holter monitoring revealed that she was in sinus rhythm with rates between 100 and 110 beats/min. Symptoms of palpitations were correlated with sinus tachycardia at rates between 120 and 150 beats/min. An electrophysiologic study demonstrated dual atrioventricular nodal physiology with sustained atrioventricular reentry. The slow pathway was ablated. Despite transient relief of her symptoms, the palpitations recurred and she had several syncopal episodes. Beta-blockers led to only minimal relief of her symptoms. Another electrophysiologic study demonstrated progressive decreases in her cycle length with increasing doses of isoproterenol. The patient underwent radiofrequency ablations of her sinoatrial node and atrial septum near the typical location of the slow pathway.

The patient remained symptomatic and was referred for surgical treatment. She underwent an off-pump, beating-heart isolation and ablation of her sinoatrial node through a right $6-\mathrm{cm}$ minithoracotomy. Intraoperative administration of isoproterenol led to sinus tachycardia with rates of 150 to 180 beats/min. A large cuff of right atrium adjoining the junction of the superior vena cava was isolated from the body of the right atrium with a bipolar radiofrequency ablation device (Figure 1). Three circumferential ablations

\footnotetext{
From the Division of Cardiothoracic Surgery a and Department of Medicine, ${ }^{\text {b }}$ Washington University School of Medicine, St Louis, Mo.

Received for publication Nov 10, 2004; accepted for publication Dec 17, 2004.

Address for reprints: Ralph J. Damiano, Jr, MD, John M. Schoenberg Professor of Surgery, Chief of Cardiac Surgery, Division of Cardiothoracic Surgery, Washington University School of Medicine, Barnes-Jewish Hospital, 3108 Queeny Tower, One Barnes-Jewish Hospital Plaza, St Louis, MO 63110 (E-mail: damianor@msnotes.wustl.edu).

J Thorac Cardiovasc Surg 2005;130:598-9

$0022-5223 / \$ 30.00$

Copyright $\odot 2005$ by The American Association for Thoracic Surgery

doi:10.1016/j.jtcvs.2004.12.026
}

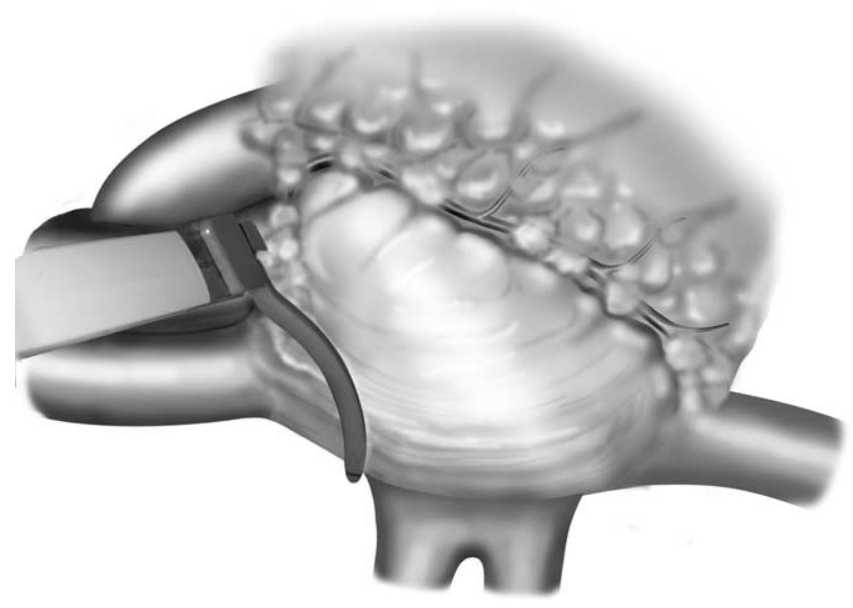

Figure 1. Position of the bipolar radiofrequency clamp (Isolator, Atricure Inc, Cincinnati, Ohio) used to isolate the sinoatrial node and surrounding right atrial tissue.

were performed, which led to a change in P-wave morphology and significant blunting in the response to isoproterenol. The average ablation time was 8.5 seconds. Bipolar pacing demonstrated that the sinoatrial node and surrounding atrium were isolated from the remainder of the heart. Beta-blockers were continued postoperatively. At the 6-month follow-up, the patient has progressively increased her level of physical activity. She has not experienced palpitations, and her electrocardiogram showed normal sinus rhythm with an inverted $\mathrm{P}$ wave.

\section{Comment}

Although IST was originally described in 1979, it has only recently been accepted as a medical condition. Patients with this debilitating condition are typically young women. IST is thought to be caused by enhanced intrinsic automaticity of the sinoatrial node or hypersensitivity to beta-adrenergic stimulation. The sinus node impulse may have a multifocal origin, and early activation sites can shift within the sinus node complex in response to autonomic influences. Treatment with beta-blockers or calcium channel blockers generally leads to only transient relief. Controversy exists regarding the efficacy and long-term success of radiofrequency catheter ablation for the treatment of drug-refractory IST. Lee and associates ${ }^{1}$ reported results in 4 patients after sinus node ablation and 12 patients after sinus node modification. Two patients had recurrences of their tachycardia after a mean period of 7 months after sinus node modification. Of the 4 patients who underwent sinus node ablation, 1 patient had ectopic atrial tachycardia and 1 patient required placement of a pacemaker. Man and colleagues ${ }^{2}$ 
reported disappointing results after radiofrequency catheter ablation in 29 patients with drug-refractory IST with only $66 \%$ of the patients remaining free of sinus tachycardia long term.

Hendry and colleagues ${ }^{3}$ excised a portion of the right atrial wall and sinoatrial node in 3 patients with IST by using cardiopulmonary bypass. Although 1 patient remained free from tachycardia 5 years after her operation, 1 patient had supraventricular tachycardia related to new ectopic atrial foci and 1 patient had junctional tachycardia, which required catheter ablation and pacemaker placement. Esmailzadeh and colleagues ${ }^{4}$ reported excision of a right atrial wall portion in a 36-year-old woman with IST after failed catheter ablation. This procedure was performed through a median sternotomy on cardiopulmonary bypass. After 6 months, there was no recurrence of sinus tachycardia. This is the first report of a minimally invasive off-pump approach for the treatment of IST. Our patient underwent epicardial bipolar radiofrequency ablation to isolate rather than excise the sinoatrial node. Surgical therapy should be reserved for patients with IST in whom drug therapy and catheter ablation fail. Experimental studies performed in sheep have shown that bipolar radiofrequency energy can produce permanent transmural linear lesions on the beating heart. ${ }^{5}$ Alternatively, catheter-based ablation does not consistently result in full-thickness lesions. Thus, this technique may fail to treat IST because of sinus node tissue that is located at or near the epicardial surface. Because the long-term success rate of drug therapy and catheter-based ablations is relatively low, advances in ablation technology and the development of less-invasive surgical techniques could be a promising alternative for these patients.

\section{References}

1. Lee RJ, Kalman JM, Fitzpatrick AP, Epstein LM, Fisher WG, Olgin JE, et al. Radiofrequency catheter modification of the sinus node for "inappropriate" sinus tachycardia. Circulation. 1995;92:2919-28.

2. Man KC, Knight B, Tse HF, Pelosi F, Michaud GF, Flemming M, et al. Radiofrequency catheter ablation of inappropriate sinus tachycardia guided by activation mapping. J Am Coll Cardiol. 2000;35:451-7.

3. Hendry PJ, Packer DL, Anstadt MP, Plunkett MD, Lowe JE. Surgical treatment of automatic atrial tachycardias. Ann Thorac Surg. 1990;49: 253-60.

4. Esmailzadeh B, Bernat R, Winkler K, Meybehm M, Pfeiffer D, Kirchhoff PG. Surgical excision of the sinus node in a patient with inappropriate sinus tachycardia. J Thorac Cardiovasc Surg. 1997;114:861-4.

5. Prasad SM, Maniar HS, Schuessler RB, Damiano RJ Jr. Chronic transmural atrial ablation by using bipolar radiofrequency energy on the beating heart. J Thorac Cardiovasc Surg. 2002;124:708-13.

\title{
Successful aortic fenestration to treat prolonged motor paralysis of the lower extremities after repair of type A aortic dissection
}

\author{
Lino Miele, MS, David J. Eschelman, MD, Stephen McNulty, D0, Rashad Choudry, MD, Evelio Rodriguez, MD,
} James Diehl, MD, and Daniel Marelli, MD, Philadelphia, $\mathrm{Pa}$

\section{An extra illustration is available online. $\mathcal{B}$}

$\mathrm{P}$

araplegia after repair of a type A aortic dissection is rare. We report a case, which resolved after fenestration was added to lumbar cerebrospinal fluid drainage.

\section{Clinical Summary}

A 44-year-old man was seen with chest pain. His troponin level was $4.4 \mu \mathrm{g} / \mathrm{dL}$. His pain persisted, and a computed tomographic scan revealed a Stanford type A aortic dissection. Echocardiogra-

From the Divisions of Cardiothoracic Surgery, Interventional Radiology, and Anesthesiology, Thomas Jefferson University Hospital, Philadelphia, Pa.

Received for publication Feb 1, 2005; accepted for publication Feb 8, 2005.

Address for reprints: Daniel Marelli, MD, Division of Cardiothoracic Surgery, Jefferson Medical College, 1025 Walnut St, Suite 607, Philadelphia, PA 19107 (E-mail: daniel.marelli@jefferson.edu).

J Thorac Cardiovasc Surg 2005;130:599-601

$0022-5223 / \$ 30.00$

Copyright $\odot 2005$ by The American Association for Thoracic Surgery

doi:10.1016/j.jtcvs.2005.02.009 phy showed preserved aortic valve anatomy without pericardial effusion. Magnetic resonance imaging (MRI) showed the origin of the dissection to be distal to the left subclavian artery, with antegrade extension to the right common iliac artery and a retrograde extension along the greater aortic curve to the right coronary artery without evidence of reentry into the aortic lumen proximally (Figure E1).

The patient underwent surgery, where findings confirmed preoperative observations. Cardiopulmonary bypass was carried out through the right axillary artery and the right atrium. The right coronary artery was occluded proximal to the crux and bypassed at the level of the posterior descending artery. The ascending aorta was replaced with a 24 Hemashield graft (Boston Scientific Corporation, Natick, Mass) after stabilization of the false lumen with BioGlue (CryoLife Inc, Kennesaw, Ga). The aorta remained clamped throughout the procedure.

On awakening, the patient was found to have complete motor paralysis of his lower extremities but with preserved sensation. Methylprednisolone was administered at a dose of $7 \mathrm{mg} / \mathrm{kg}$. Lumbar drainage was instituted with a Codman catheter (Codman and Shurtleff, Inc, Raynham, Mass), adjusted to maintain a cerebrospinal fluid pressure of $7 \mathrm{~cm} \mathrm{H}_{2} \mathrm{O}$. The patient was weaned from mechanical ventilation. Motor paralysis persisted.

A fenestration procedure was initiated 24 hours postoperatively, 16 hours after the paralysis was first noticed. With the 